\title{
Foliar Raffinose and Sucrose in Four Conifer Species: Relationship to Seasonal Temperature
}

\author{
L.E. Hinesley', D.M. Pharr ${ }^{2}$, L.K. Snelling ${ }^{3}$, and S.R. Funderburk ${ }^{4}$ \\ Department of Horticultural Science and Plant Physiology Program, North Carolina State \\ University, Raleigh, NC 27695-7609
}

Additional index words. Juniperus virginiana, Pinus strobus, Pinus virginiana, Cupressocyparis leylandii, Christmas trees, dormancy, cold hardiness

\begin{abstract}
Foliar raffinose and sucrose concentrations in eastern white pine (Pinus strobus L.), eastern redcedar (J uniperus virginiana L.), Leyland cypress ( $x$ C upressocyparis leylandii $D$ allim.), and Virginia pine ( $P$ inus virginiana L.) were measured monthly over 2 years. During cold weather, foliage of white pine and redcedar contained higher concentrations of raffinose and sucrose than did Leyland cypress and Virginia pine. $R$ afflnose concentrations were highest during winter and were best correlated with the frequency of occurrence of daily minima $\leq 1.7 \mathrm{C}$ during the 30 days before sampling. Sucrose concentrations, which also reached maximum levels during the winter, were best correlated with the frequency of occurrence of daily minima $\leq 7.2 \mathrm{C}$ in the prior 30 days. Sucrose concentrations were relatively high during fall and spring. $R$ affinose and sucrose concentrations increased in response to recurring low temperature, with correlations highest for raffinose.
\end{abstract}

In the fall and winter, foliar raffinose concentration increases in conifers (Little, 1970; Parker, 1959). Raffinose accumulates in Fraser fir [Abies fraseri (Pursh) Poir.] in response to low temperature and short days (Mitcham-Butler et al., 1986). This response is not confined to higher plants. A brief cold treatment (4C) of algae (Chlorella vulgaris Beyerinck) induces an accumulation of raffinose, and concentrations decrease when the algae are transferred to warmer temperatures (Salerno and Pontis, 1989). In general, high foliar raffinose concentrations are associated with greater cold hardiness (Kandler and Hopf, 1980; Parker, 1959).

Fraser fir Christmas trees that are harvested after experiencing low temperatures have higher foliar raffinose concentration and exhibit better postharvest needle retention than trees preconditioned with higher temperatures (Mitcham-Butler et al., 1986). Although raffinose increases in the foliage of several conifers during the winter and might be involved in cold hardiness, there are no studies that compare seasonal sugar levels of different conifer species growing in the same environment. Thus, comparisons among species from available data are difficult. Our research had two objectives: 1) determine seasonal raffinose and sucrose concentrations in the foliage of four conifer species that differ in hardiness and are important to the Christmas tree industry and 2) determine if foliar raffinose and sucrose concentrations are correlated with the occurrence of different baseline (daily minimum) temperatures during the week or month preceding sampling.

\section{Materials and Methods}

Four conifers were studied: eastern redcedar, eastern white pine, Virginia pine, and Leyland cypress. Leyland cypress is a

Received for publication 20 Nov. 1991. Accepted for publication 4 May 1992. This research was funded by the North Carolina Agricultural Research Service, Raleigh, NC 27695-7643. We gratefully acknowledge the assistance of $\mathrm{Ka}$ tharine B. Perry in the analysis of temperature data. Use of trade names does not imply endorsement of products named nor criticism of similar ones not mentioned. The cost of publishing this paper was defrayed in part by the payment of page charges. Under postal regulations, this paper therefore must be hereby marked advertisement solely to indicate this fact.

'Professor. Dept. of Horticultural Science.

${ }^{2}$ Professor. Dept. of Horticultural Science and Plant Physiology Program.

${ }^{3}$ Research Technician. Dept. of Horticultural Science.

${ }^{4}$ Research Technician. Dept. of Horticultural Science. hybrid between Alaska cedar [Chamaecyparis nootkatensis (D. Don) Spach] and Monterey cypress (Cupressus macrocarpa Hartweg.). Trees were 1.5- to 2.0-m tall, had been cultured as Christmas trees, and were growing on a uniform site in adjacent rows on a research farm in Raleigh, N.C. The distance separating the most widely spaced sample trees was no more than $30 \mathrm{~m}$. Beginning 1 Apr. 1989, and at monthly intervals thereafter, foliage was collected from five trees of each species over 2 years. The same trees of each species were used throughout the study. On each sampling date, $\approx 100$ fascicles were composited from various positions throughout the upper crown of each pine tree. For redcedar and Leyland cypress, 15 to 20 small branch tips (6- to 8-cm long) were used. With the pines, currentyear fascicles were used beginning in June, when new needles were about half the length of 1-year-old needles and could be removed without tearing the bark. Foliage samples were placed on ice, transported a short distance to North Carolina State Univ., and stored at $-30 \mathrm{C}$ pending analysis.

Samples were freeze-dried, ground through a 20-mesh screen, and stored in a dessicator at $22 \mathrm{C}$ before analysis. Samples (50 $\mathrm{mg}$ ) were weighed and extracted twice for $5 \mathrm{~min}$ with hexane (boiling point range 37 to $55 \mathrm{C}$ ) in a $42 \mathrm{C}$ water bath under a fume hood. Samples were centrifuged, supernatants discarded, and remaining pellets were extracted three times with $80 \%$ aqueous ethanol $(\mathrm{v} / \mathrm{v})$ at $80 \mathrm{C}$ to remove soluble sugars. The ethanolic supernatant solutions were collected, evaporated to dryness in vacuo at $45 \mathrm{C}$, resolubilized in $1 \mathrm{ml}$ of distilled water, and stored at $-80 \mathrm{C}$ until analyzed.

Raffinose and sucrose concentrations were determined by highperformance liquid chromatography. The system consisted of a Waters (Millipore, Waters Chromatography Division, Milford, Mass.) 6000A pump, a Waters Sugar-Pak column, and a Waters 410 Differential Refractometer. Water was used as the solvent at a flow rate of $0.5 \mathrm{ml} \cdot \mathrm{min}^{-1}$. The column was operated at $75 \mathrm{C}$ and was preceded by a single Waters $\mu$-Bondapak $\mathrm{C}_{18} /$ Corasil guard and a set of anion and cation guard cartridges operated at 22C (Bio-Rad, Richmond, Calif., deashing guards). Following dilution, samples were injected, and sugars were identified and quantified using an SP4200 computing integrator (Spectra-Physics, San Jose, Calif.).

Daily maximum and minimum temperatures (Fig.1) were obtained from a standard weather station located $200 \mathrm{~m}$ from the trees and on the same contour. The frequency of days in which 


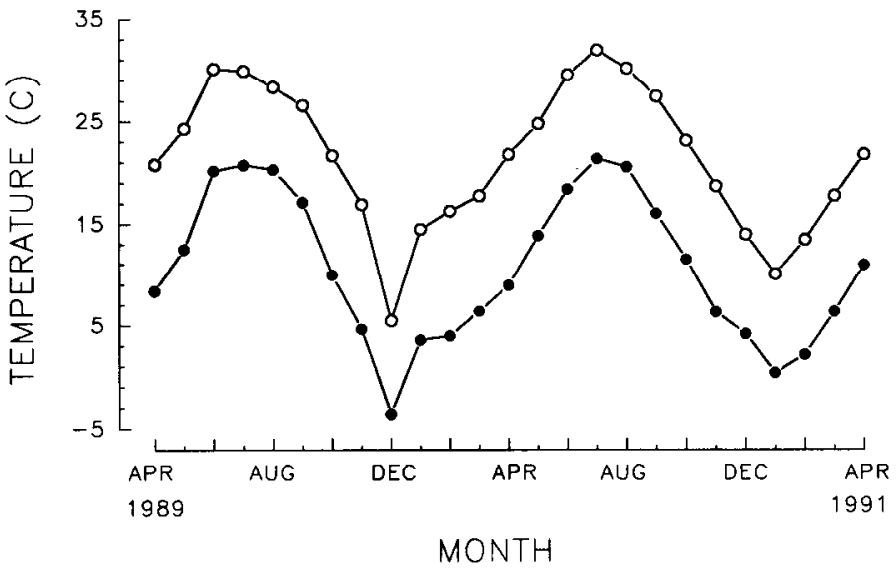

Fig. 1. Average monthly maximum ( $\bigcirc$ ) and minimum ( $\bigcirc$ ) air temperatures over 2 years (Apr. 1989 to Apr. 1991) on the site where Virginia pine, Leyland cypress, eastern white pine, and eastern redcedar were sampled monthly for foliar raffinose and sucrose.

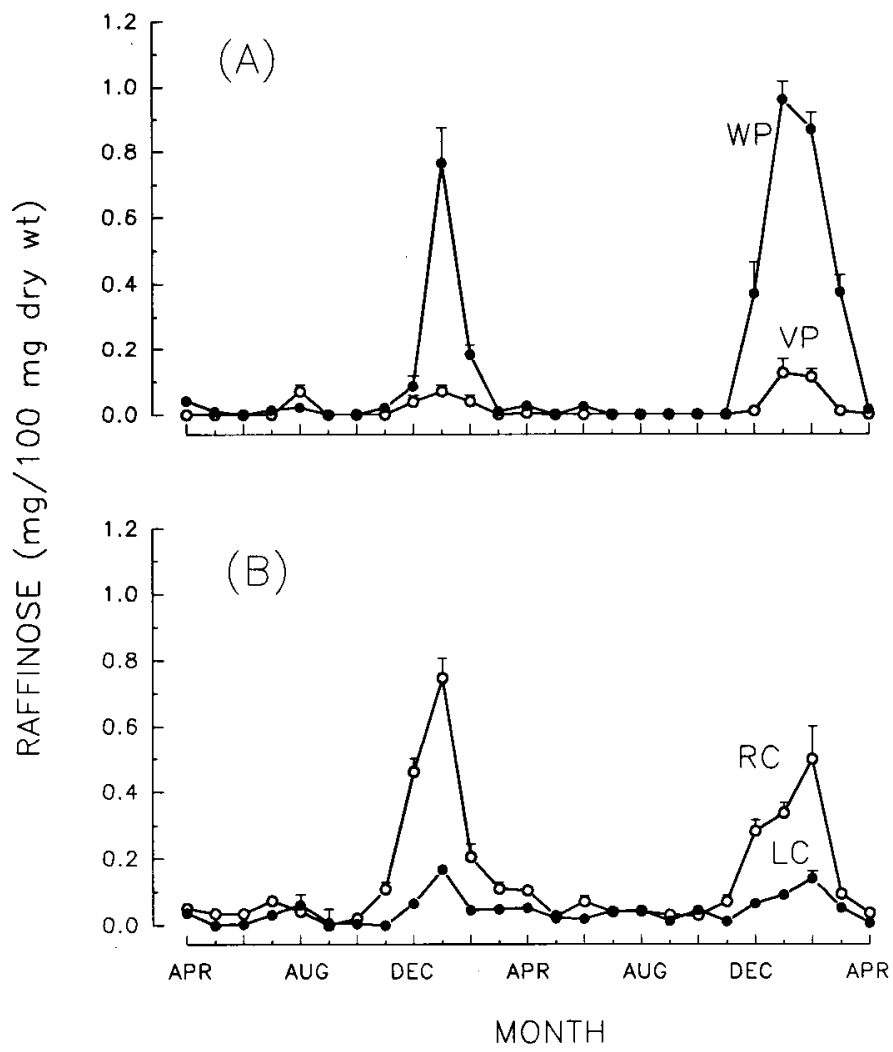

Fig. 2. Monthly variation in foliar raffinose over 2 years for four Christmas tree species. (A) eastern white pine (WP, - ); Virginia pine $(\mathrm{VP}, \mathrm{O})$. (B) eastern redcedar ( $\mathrm{RC}, \mathrm{O})$; Leyland cypress (LC, - ). Vertical bars $=\mathrm{SE} ; \mathrm{n}=5$.

the minimum (baseline) temperature was $\leq 15.6,12.8,10.0$, $7.2,5.0,1.7,-1.1$, and $-5.0 \mathrm{C}$ was determined for the 30 days preceding each sampling date. Resulting frequencies for each baseline temperature were correlated with foliar raffinose and sucrose concentrations using SAS (SAS Institute, Cary, N.C.). Linear regressions were developed for raffinose and sucrose concentration as a function of frequency of occurrence of baseline temperature using the highest correlations.
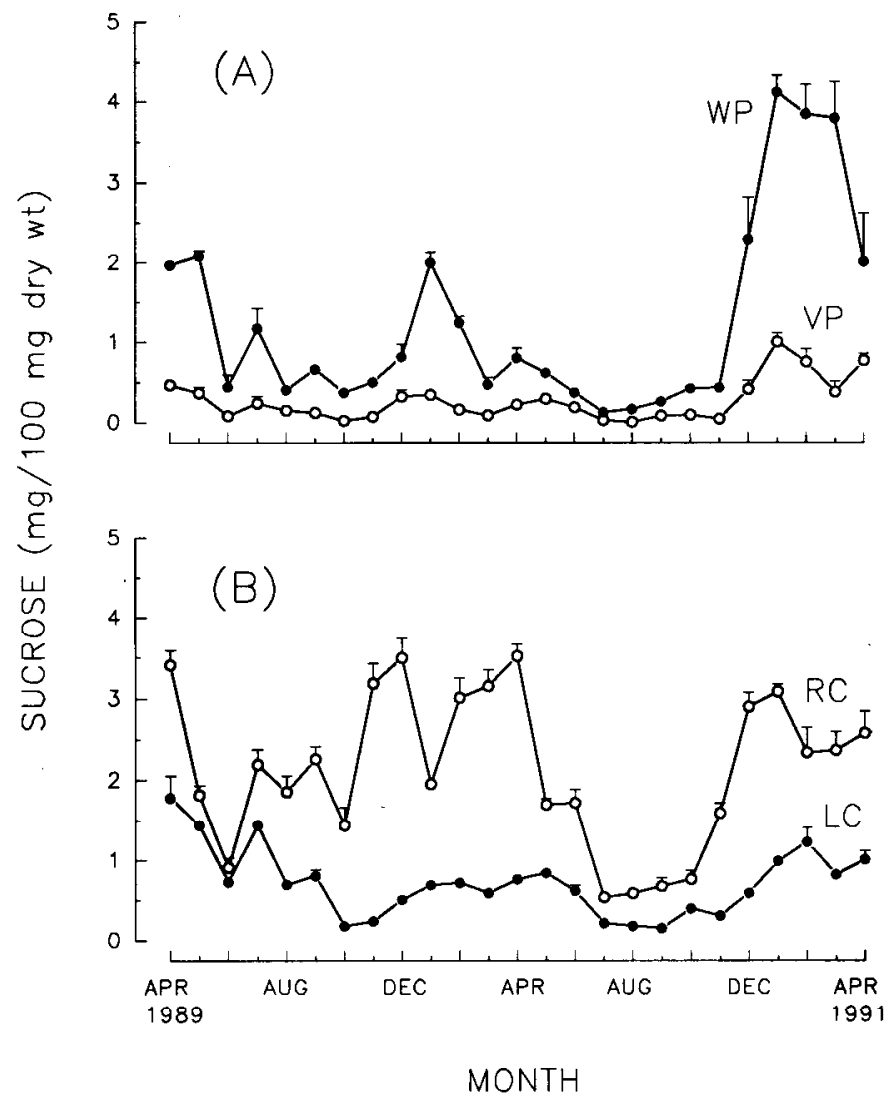

Fig. 3. Monthly variation in foliar sucrose over 2 years for four Christmas tree species. (A) eastern white pine (WP, $)$ and Virginia pine (VP, $\mathrm{O}$ ). (B) eastern redcedar (RC, $\mathrm{O}$ ); Leyland cypress (LC,

). Vertical bars $=\mathrm{SE} ; \mathrm{n}=5$.

\section{Results and Discussion}

Foliar concentrations of raffinose increased for all species during winter (Fig. 2), with accumulation most pronounced in white pine and redcedar. Peak values for these species in December and January were 0.8 to $1.1 \mathrm{mg} / 100 \mathrm{mg}$ dry weight, compared to maximum values $\leq 0.2 \mathrm{mg} / 100 \mathrm{mg}$ dry weight in Virginia pine and Leyland cypress. Concentrations were very low during the warm months of May through September (Fig. 2). The two species (white pine and redcedar) that produced the most foliar raffinose during the winter maximized foliar sucrose at the same time (Fig. 3). Similar patterns have been documented for other conifers (Kozlowski and Keller, 1966; Kreuger and Trappe, 1967; Parker, 1963). In general, foliage contained more sucrose than raffinose. Compared to the other species, redcedar contained higher foliar sucrose concentrations during late fall and early spring.

Foliar concentrations of raffinose in redcedar, Virginia pine, and white pine were most highly correlated with the frequency of occurrence of temperatures $\leq 1.7 \mathrm{C}$ in the prior 30 days (Fig. 4A). Concentrations in Leyland cypress were only slightly more correlated with temperatures $\leq 1.1 \mathrm{C}$. Except for redcedar, foliar sucrose levels were best correlated with the frequency of occurrence of daily minimum temperatures $\leq 7.2 \mathrm{C}$ in the previous 30 days (Fig. 4B). With redcedar, the correlation was slightly higher with a baseline temperature of 10C.

Whether accumulation and maintenance of high foliar raffinose concentrations is a short-term response to a few cold events (induction) or a cumulative, longterm effect from recurring ex- 


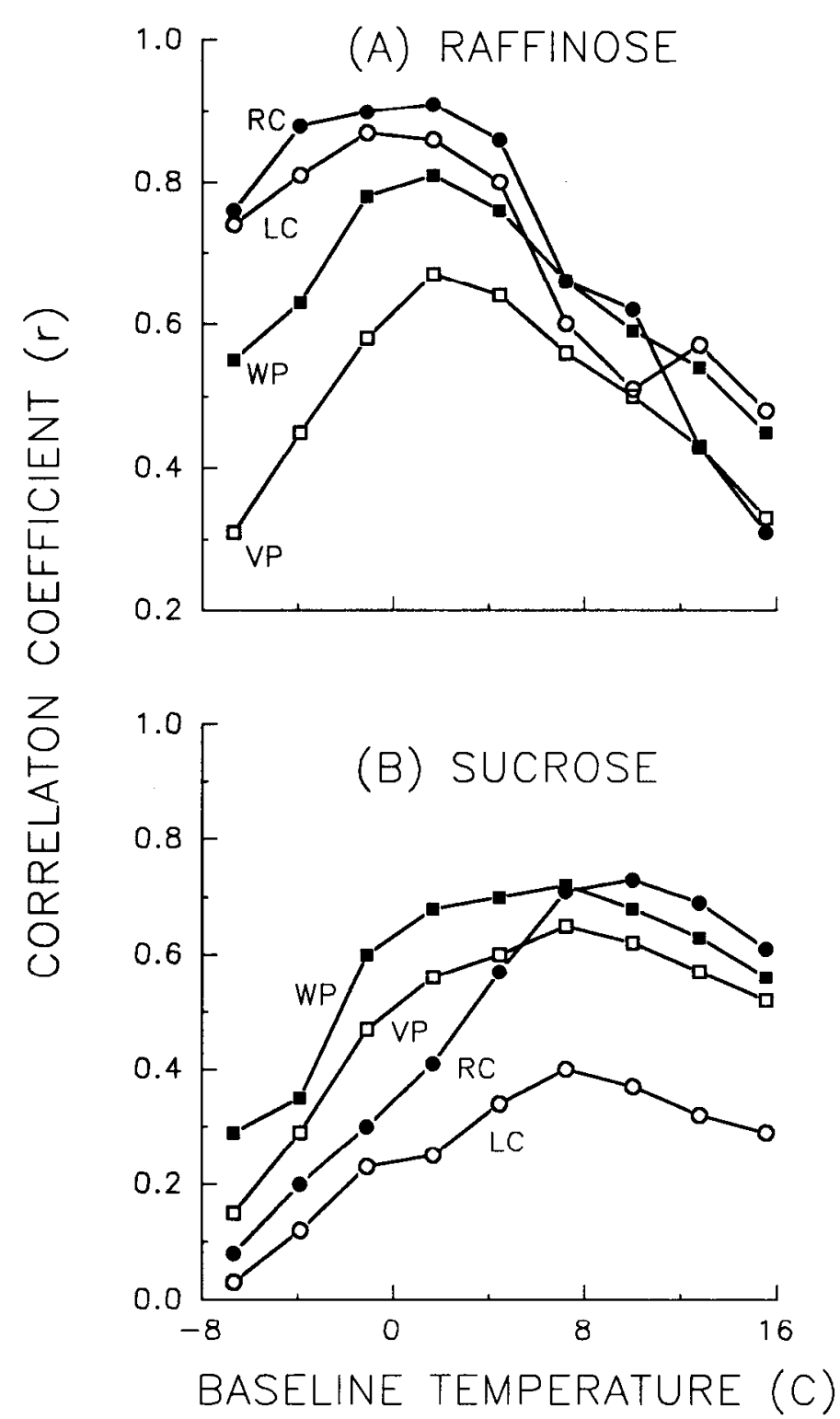

Fig. 4. Coefficients for the correlation between foliar raffinose (A) or sucrose (B) and the frequency of days (during the 30 days before sampling) with a minimum temperature equal to or less than specified baseline temperatures. Correlation coefficients are plotted against baseline temperatures from which frequencies were calculated. Eastern redcedar (RC, $\bigcirc$ ); Leyland cypress (LC, $\bigcirc$ ); eastern white pine (WP, $\mathbf{\square}$ ); and Virginia pine (VP, $\square$ ).

posure to low temperatures is unknown. However, frequent exposure to low temperatures appears to be important (Figs. 3 and 5). In controlled environments, Fraser fir kept at a $12 / 6 \mathrm{C}$ (day/ night) cycle regime gradually accumulated (sigmoid pattern) foliar raffinose over 8 weeks up to levels approaching those in field grown trees during the winter (Mitcham-Butler, 1986).

With respect to foliar raffinose and sucrose studied here, there were clearly two groups: 1 ) species that accumulated high concentrations during cold weather (white pine and redcedar) and 2) species that did not (Virginia pine and Leyland cypress). Grouping of the four species with respect to accumulation of raffinose conforms well with their ratings for cold hardiness. According to the hardiness map of the Arnold Arboretum at Harvard Univ. (Dirr, 1990), white pine, redcedar, Virginia pine, and Leyland cypress are hardy in zones 2, 3, 4, and 6, respec-
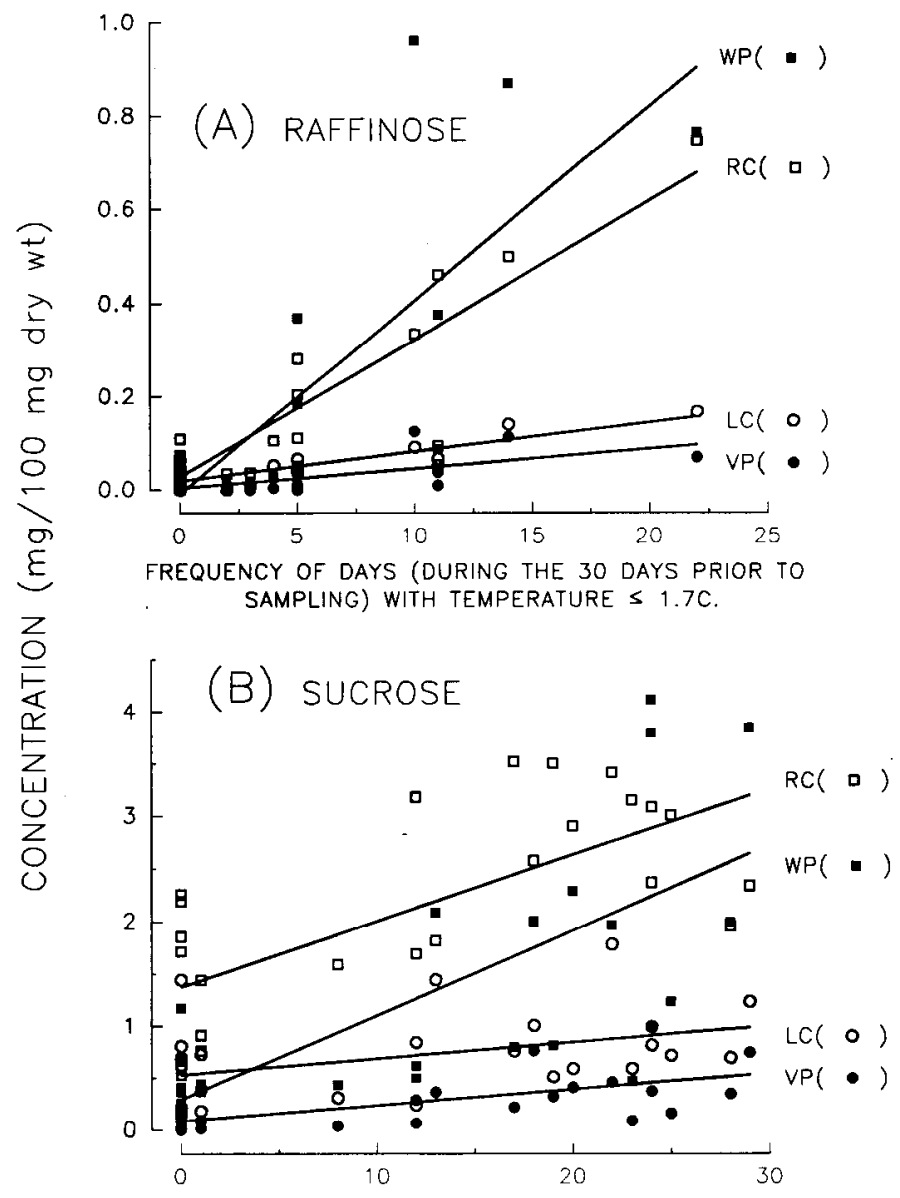

FREQUENCY OF DAYS (DURING THE 30 DAYS PRIOR TO SAMPLING) WITH TEMPERATURE $\leq 7.2 \mathrm{C}$

Fig. 5. (A) Relationship of foliar raffinose concentration to the frequency of days (during the 30 days before sampling) in which the minimum temperatures was $\leq 1.7 \mathrm{C}$. In the linear regression, values for intercept, slope, and $R^{2}$ were as follows: white pine $(-0.009$, $0.042,0.66)$; redcedar $(0.027,0.030,0.83)$; Leyland cypress $(0.019$, $0.0063,0.74)$; and Virginia pine $(0.0027,0.0043,0.43)$. All slopes were significant $(P \leq 0.05)$. (B) Relationship of foliar sucrose concentration to the frequency of days (during the 30 days before sampling) in which the minimum temperature was $\leq 7.2 \mathrm{C}$. In the linear regression, values for intercept, slope, and $R^{2}$ were as follows: white pine $(0.29,0.081,0.53)$; redcedar $(1.38,0.063,0.50)$; Leyland cypress $(0.53,0.016,0.16)$; and Virginia pine $(0.084,0.015,0.42)$. All slopes were significant $(P \leq 0.05)$.

tively (lower numbers signify greater hardiness). White pine and redcedar have an extensive north to south geographic range (U.S. Dept. Agr., 1965), so hardiness might vary with provenance.

Although there was considerable variation, foliar concentrations of raffinose and sucrose in redcedar and white pine increased by 0.030 to $0.042 \mathrm{mg} / 100 \mathrm{mg}$ dry weight, respectively, in response to each occurrence of daily minimum temperatures $\leq 1.1 \mathrm{C}$ in the 30 days before sampling (Fig. 5A). Accumulation rates for Leyland cypress and Virginia pine were similar to each other, but much lower than those for redcedar and white pine. Correlations between sucrose and the occurrence of low temperature were much lower than those for raffinose and low temperature in three of the four species (Fig. 5). Nevertheless, frequent occurrence of low temperature was generally associated with increased foliar sucrose in redcedar and white pine (Fig. $5 \mathrm{~B}$ ), and these two species contained higher foliar sucrose than Virginia pine and Leyland cypress during the fall and winter 
months (Figs. 2 and 3). While the effect of recurring low temperature on sucrose concentration was generally weaker than for raffinose, its effect in all four species was significant, as indicated by significant $(P \leq 0.05)$ values for slopes in the linear regressions of concentration vs. frequency of days $\leq 7.2 \mathrm{C}$ (Fig. 5B). Foliar sucrose concentrations (mg/100 mg dry weight) increased in response to each occurrence of daily minimum temperatures $\leq 7.2 \mathrm{C}$ in the 30 days before sampling as follows based on Fig. 5: redcedar (0.063), white pine (0.081), Leyland cypress (0.016), and Virginia pine (0.015).

Foliar sucrose accumulated at higher temperatures than did raffinose (Figs. 3 and 4). The four species, however, did not differ appreciably in respect to the low temperature at which the maximum correlation was obtained with accumulation of a given sugar (Fig. 4A and B). This pattern suggests that the four species were about equal in perception of the range of low temperatures that promoted accumulation of foliar sugars (Fig. $4 \mathrm{~A}$ and $\mathrm{B}$ ), although the most effective temperatures were different for raffinose and sucrose. One factor associated with differences in winter sugar levels among the species appeared to be variation in the rate of sugar accumulation in response to the frequency of a given low temperature, as opposed to a difference in the threshold temperature sensed by a given species (Figs. 4 and 5). The relatively high sugar concentrations in the winter foliage of white pine and redcedar might be one factor that contributes to the greater hardiness of these species, compared to Leyland cypress and Virginia pine. In some winter environments, the foliage of conifers frequently experiences subfreezing temperatures as well as substantial moisture stress (Lindsay, 1971; Tranquillini, 1979). Elevated sugar concentration decreases the water potential of foliar cells by increasing their osmotic pressure, and high solute concentration also depresses the freezing point of the cellular water. The fact that raffinose occurred at substantially lower concentration than sucrose and occurred at peak concentration only during the coldest weather raises the question as to whether raffinose has a more specific role in hardiness apart from its role as a solute. Raffinose and other oligosaccharides might confer dessication tolerance to seeds by preventing crystallization of sucrose during the drying of seeds (Koster and Leopold, 1988). Perhaps raffinose has a similar role in cold tolerance, preventing sucrose crystallization in extreme cold where the combined effects of foliar drought and cold temperature might promote sucrose crystallization and a loss of any cryoprotective effects of this sugar. In this regard, the two high-sucrose species studied here were the species in which raffinose increased the most. It will be of interest to learn if this relationship between sucrose, raffinose, and hardiness holds over a wide range of coniferous species.

From a practical point of view, raffinose and sucrose concentrations in the four conifer species were positively correlated with occurrence of low temperature. However, these relationships were specific for a given species and were not sufficiently strong to have good predictive value. For predictive models, inclusion of environmental variables such as daylength, negating temperatures, drought effects, or other unknown factors might be necessary.

\section{Literature Cited}

Dirr, M.A. 1990. Manual of woody landscape plants: Their identification, ornamental characteristics, culture, propagation and uses. 4th ed. Stipes Publishing Co., Champaign, Ill.

Kandler, O. and H. Hopf. 1980. Occurrence, metabolism, and function of oligosaccharides, p. 221-270. In: J. Preiss (ed.). The biochemistry of plants (vol. 3), carbohydrates: Structure and function. Academic, New York.

Koster, K.L. and A.C. Leopold. 1988. Sugars and dessication tolerance in seeds. Plant Physiol. 88:829-832.

Kozlowski, T.T. and T. Keller. 1966. Food relations of woody plants. Bot. Rev. 32:293-382.

Kreuger, K.W. and J.M. Trappe. 1967. Food reserves and seasonal growth of Douglas-fir seedlings. For. Sci. 13:192-202.

Lindsay, J.H. 1971. Annual cycle of leaf water potential in Picea engelmannii and Abies lasciocarpa at timberline in Wyoming. Arctic Alpine Res. 3:131-138.

Little, C.H.A. 1970. Seasonal changes in carbohydrate and moisture content in needles of balsam fir (Abies balsamea). Can. J. Bot. 48:2021-2028.

Mitcham-Butler, E.J., L.E. Hinesley, and D.M. Pharr. 1986. Soluble carbohydrate concentration of Fraser fir foliage and its relationship to postharvest needle retention. J. Amer. Soc. Hort. Sci. 112:672676.

Parker, J. 1959. Seasonal changes in white pine leaves: A comparison of cold resistance and free-sugar fluctuations. Bot. Gaz. 121:46-50.

Parker, J. 1963. Cold resistance in woody plants. Bot. Rev. 29:123201.

Salerno, G.L. and H.G. Pontis. 1989. Raffinose synthesis in Chlorella vulgaris cultures after a cold shock. Plant Physiol. 89:648-651.

SAS Institute. 1985. SAS user's guide: Statistics. version 5. SAS Institute, Gary, N.C.

Tranquillini, W. 1979. Physiological ecology of the alpine timberline: Tree existence at high altitudes with special reference to the European Alps. Ecol. Studies 31. Springer-Verlag, Berlin.

U.S. Dept. of Agriculture. 1965. Silvics of forest trees of the United States. Agr. Hdbk. 271 